\title{
Influence of building characteristics on tunnelling-induced ground movements
}

\author{
S. RITTER*, G. GIARDINA†, M. J. DEJONG* and R. J. MAIR*
}

\begin{abstract}
The interaction mechanisms between surface structures and tunnelling-induced ground movements were investigated through centrifuge testing. Although numerous studies have considered this soil-structure interaction problem, previous experiments have neglected important building characteristics and field data inherently contain numerous uncertainties related to the soil, the structure and the tunnelling procedure. Consequently, the interpretation of results and validation of computational models can be problematic. In this study, tunnelling beneath three-dimensional printed structural models with varying building characteristics (i.e. position, length and facade openings) was simulated in a centrifuge. The experimental results demonstrate that tunnelling induces soil displacements at the surface and subsurface that are notably altered due to nearby structures. Specifically, different amounts of vertical and horizontal ground movements, soil dilation and widening of settlement troughs were observed. Building distortions and horizontal building strains were also affected by the relative position of the building to the tunnel, the building length and the area of facade openings. The experimental results provide important data for the evaluation of current design methods and verification of computational models.
\end{abstract}

KEYWORDS: centrifuge modelling; soil/structure interaction; tunnels \& tunnelling

\section{INTRODUCTION}

Predicting building response to tunnelling-induced settlement is essential for urban tunnelling projects, but remains a challenge due to the complex soil-structure interaction. In particular, finite-element analysis results have shown the critical role played by the building stiffness (Potts \& Addenbrooke, 1997; Franzius et al., 2006; Goh \& Mair, 2012) and the building weight (Franzius et al., 2004; Giardina et al., 2015a). Parametric studies have enabled the translation of such modelling results into empirical design methods (Potts \& Addenbrooke, 1997; Franzius et al., 2006; Goh \& Mair, 2012; Giardina et al., 2015a).

These so-called relative stiffness approaches, which relate the building stiffness to the soil stiffness, compare the actual settlements with the settlements in greenfield conditions, where no buildings are present. For most cases, the greenfield settlement profiles transverse to the tunnel are described by a Gaussian curve (Peck, 1969; Schmidt, 1969). Typically, these settlement profiles are predicted by making assumptions on the tunnelling-induced ground loss and the width of the settlement trough, which both depend on the tunnelling method and the ground conditions. The potential soilstructure interaction during the tunnelling procedure is then considered using modification factors, which quantify the alteration of greenfield displacements as a function of the given relative building stiffness. Fig. 1 conceptually depicts the modification of the vertical soil displacements above a tunnel due to a nearby structure and defines the deflection

Manuscript received 30 January 2017; revised manuscript accepted 4 July 2017. Published online ahead of print 21 August 2017.

Discussion on this paper closes on 1 March 2018, for further details see p. ii.

Published with permission by the ICE under the CC-BY license. (http://creativecommons.org/licenses/by/4.0/)

* Department of Engineering, University of Cambridge, Cambridge, UK.

$\dagger$ Department of Architecture and Civil Engineering, University of Bath, Bath, UK. ratios ( $D R \mathrm{~s})$ of the building settlement profile and the greenfield equivalent. For structures spanning the point of inflection, $i$, of the vertical settlement profile, it is commonly assumed to separate a building into its hogging and sagging region (Mair et al., 1996). Potts \& Addenbrooke (1997) quantified the soil-structure interaction in terms of modification factors $(M)$ for the deflection ratio as

$$
\begin{gathered}
M^{D R_{\mathrm{sag}}}=\frac{D R_{\mathrm{sag}, \mathrm{Str}}}{D R_{\mathrm{sag}, \mathrm{GF}}} \\
M^{D R_{\mathrm{hog}}}=\frac{D R_{\mathrm{hog}, \mathrm{Str}}}{D R_{\mathrm{hog}, \mathrm{GF}}}
\end{gathered}
$$

Modification factors for the horizontal strain were also defined to estimate a potential change of the horizontal greenfield ground strains due to a nearby structure (Potts \& Addenbrooke, 1997) as

$$
\begin{aligned}
M^{\varepsilon_{\mathrm{hc}}} & =\frac{\varepsilon_{\mathrm{hc}, \mathrm{Str}}}{\varepsilon_{\mathrm{hc}, \mathrm{GF}}} \\
M^{\varepsilon_{\mathrm{ht}}} & =\frac{\varepsilon_{\mathrm{ht}, \mathrm{Str}}}{\varepsilon_{\mathrm{ht}, \mathrm{GF}}}
\end{aligned}
$$

where $\varepsilon_{\mathrm{hc}}$ and $\varepsilon_{\mathrm{ht}}$ are the compressive and tensile horizontal strains of the structure (Str) or the greenfield equivalent (GF).

Although these relative building stiffness methods highlight the soil-structure interaction effects, surface structures are simplified as elastic beams and building characteristics (e.g. facade openings or non-linear material behaviour) are not considered. Consequently, uncertainty still exists about the impact of building features on this interaction problem. Furthermore, the extent to which horizontal ground strains are transferred to buildings is still debated. As a consequence, predictions based on these relative stiffness methods might differ and, in certain scenarios, can lead to underestimation of building risk to tunnel excavation (Camós et al., 2014).

The primary data for validating current design approaches are provided by case studies of building performance to tunnel excavation. However, field data are frequently affected 


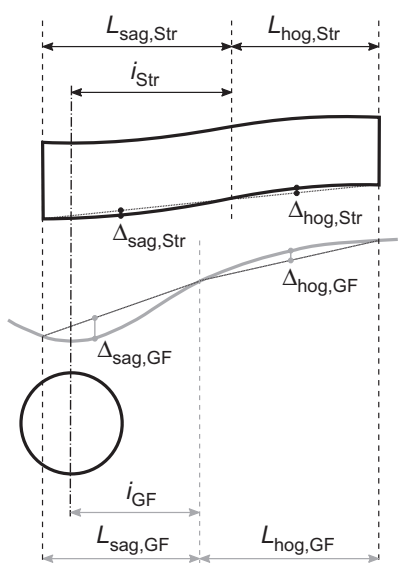

(a)

$$
\begin{aligned}
& D R_{\text {sag,str }}=\frac{\Delta_{\text {sag,Str }}}{L_{\text {sag,Str }}} \\
& D R_{\text {hog,str }}=\frac{\Delta_{\text {hog,Str }}}{L_{\text {hog,Str }}} \\
& D R_{\text {sag, GF }}=\frac{\Delta_{\text {sag, GF }}}{L_{\text {sag, GF }}} \\
& D R_{\text {hog,GF }}=\frac{\Delta_{\text {hog,GF }}}{L_{\text {hog,GF }}}
\end{aligned}
$$

(b)
Fig. 1. (a) Influence of soil-structure interaction on building distortions. (b) Definition of the relative deflection ratios (DRs) for the structure (Str) and the greenfield (GF) in sagging and hogging

by various sources of uncertainty, including the tunnelling procedure, the ground conditions and the nature of the existing buildings, and thus interpretation can be problematic. Moreover, reported soil-structure interaction data are frequently based on monitoring points located on the building facade (e.g. Frischmann et al., 1994; Lu et al., 2001; Viggiani \& Standing, 2001; Bilotta et al., 2017) and information about the soil behaviour below the structure is scarce. Experimental laboratory studies can provide a controlled environment to study the interaction between existing surfaces structure and tunnel excavation. Specifically, centrifuge models, which replicate prototype stress conditions in the soil and the building model, have provided useful data (Taylor \& Grant, 1998; Caporaletti et al., 2006; Farrell \& Mair, 2010). However, these studies were limited by relatively few building positions and rather simple building models, which can result in uncertainty when assessing building performance. For example, numerous researchers have noted that ignoring facade openings can substantially overestimate the building bending stiffness (e.g. Melis \& Rodriguez Ortiz, 2001; Son \& Cording, 2007; Dimmock \& Mair, 2008; Goh \& Mair, 2011).

The main aim of the work reported in this paper was to gain better understanding of the influence of building position and features on the tunnel-soil-building interaction problem. Therefore, the effects of building location, length and facade openings on the soil and building response were experimentally investigated. Results from a series of centrifuge model tests involving realistic three-dimensional (3D) printed building models exposed to a shallow tunnel excavation in dry, dense sand are presented. After introducing the centrifuge modelling set-up, the differences between greenfield soil displacements and ground movements modified by the building models are summarised. The effect of varying building features on structural performance is then measured by means of building deformation parameters (i.e. deflection ratio and horizontal strain), and soil-structure interaction effects are quantified in terms of modification factors.

\section{PHYSICAL MODELLING}

Centrifuge experiments at an acceleration level, $N$, of 75 times the Earth's gravity field, $\boldsymbol{g}$, were performed. Fig. 2 provides the basic dimensions of the centrifuge model, which replicates a 75 times larger tunnelling project with a cover-to-tunnel diameter ratio, $C / D$, of $1 \cdot 35$. While the soil conditions were kept constant, the building eccentricity, $e$, the building length, $L$, and the area of facade openings, $O$, varied between tests, as summarised in Fig. 3. The results of a greenfield test performed by Farrell (2010), which replicated the identical tunnelling prototype, are also presented in this paper.

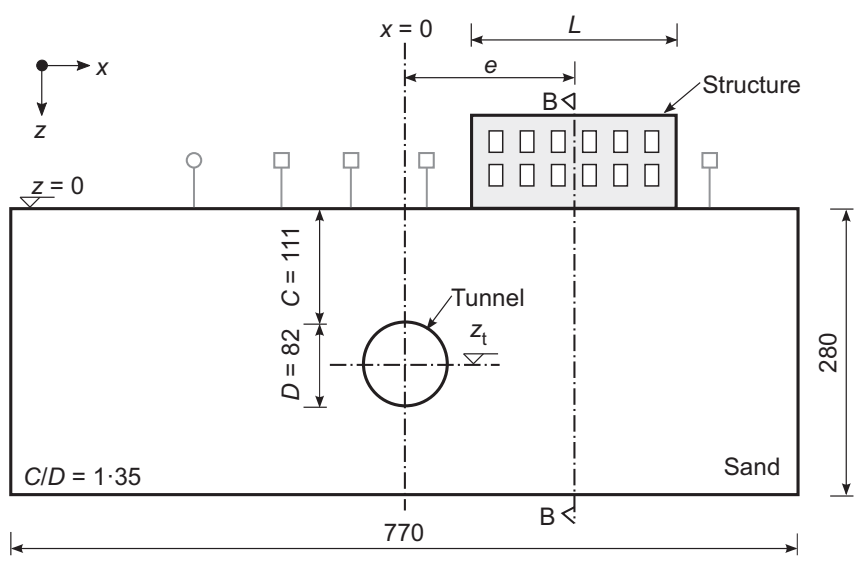

(a)

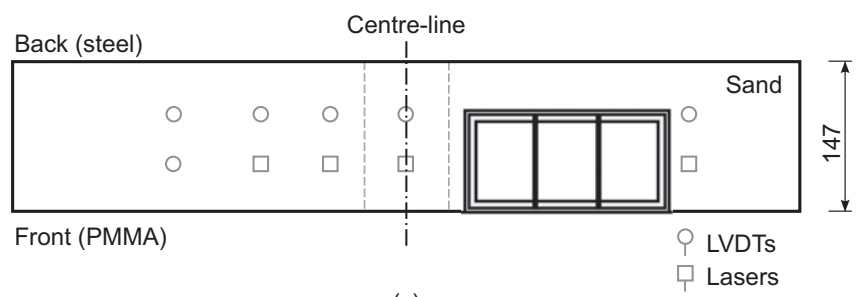

(c)

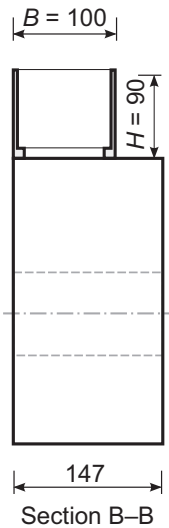

(b) 


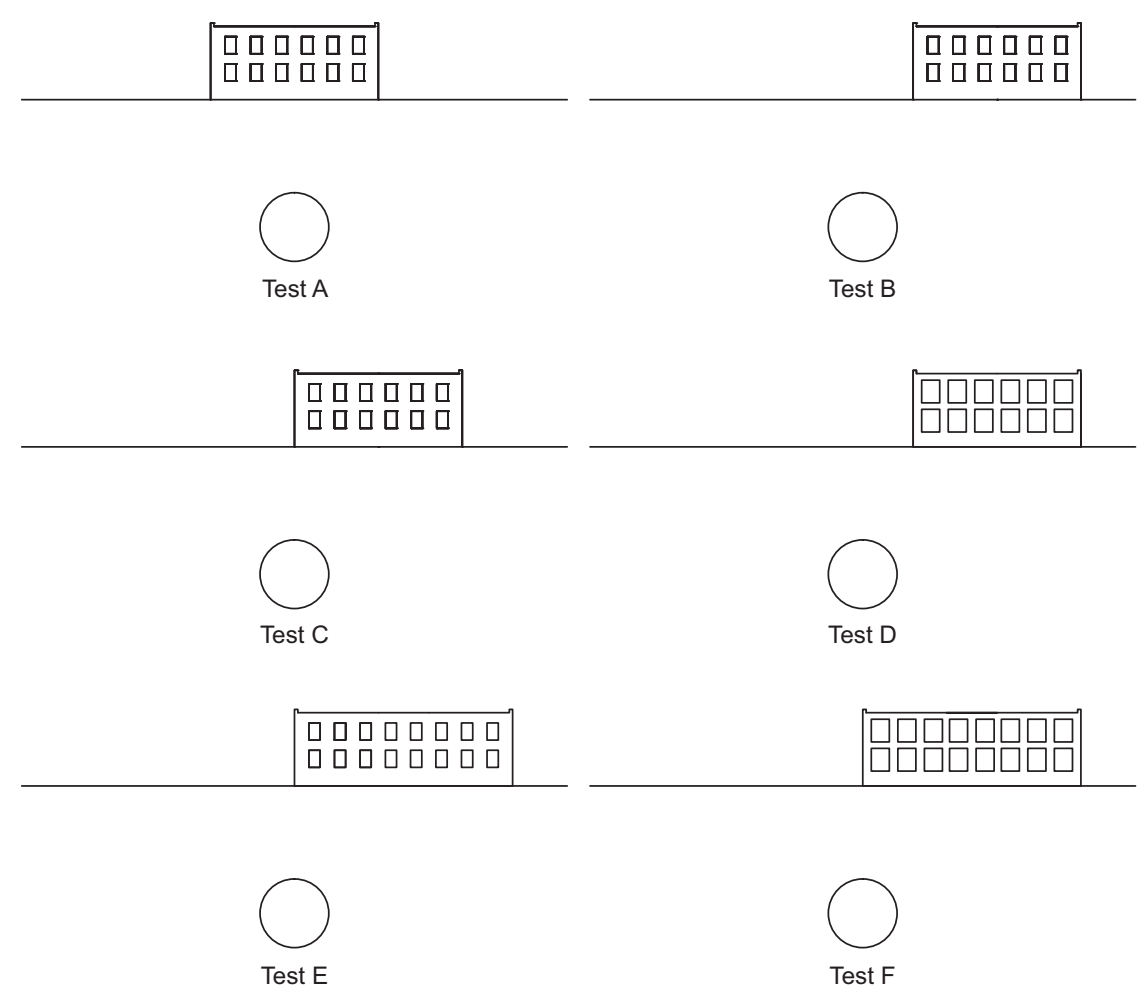

Fig. 3. Centrifuge test series with varying building length $L$, building position $e$ and facade openings $O$ : test $\mathrm{A}, e / L=0, L / H=2 \cdot 2, O=20 \% ;$ test $\mathrm{B}, e l L=0 \cdot 8, L I H=2 \cdot 2, O=20 \%$; test $\mathrm{C}, e l L=0 \cdot 5, L I H=2 \cdot 2, O=20 \%$; test $\mathrm{D}, e l L=0 \cdot 8, L I H=2 \cdot 2, O=40 \%$; test $\mathrm{E}, e l L=0 \cdot 5, L / H=2 \cdot 9$, $O=20 \%$; test F, elL $L \cdot 5, L I H=2 \cdot 9, O=40 \%$

Table 1. Physical properties of Leighton Buzzard fraction E silica sand (Haigh \& Madabhushi, 2002)

\begin{tabular}{l|l}
\hline Property & Value \\
\hline$D_{10}$ grain size: $\mathrm{mm}$ & $0 \cdot 095$ \\
$D_{50}$ grain size: $\mathrm{mm}$ & $0 \cdot 14$ \\
$D_{60}$ grain size: $\mathrm{mm}$ & $0 \cdot 15$ \\
Minimum voids ratio, $e_{\min }$ & $0 \cdot 613$ \\
Maximum voids ratio, $e_{\max }$ & $1 \cdot 014$ \\
Specific gravity, $G_{\mathrm{s}}$ & $2 \cdot 67$ \\
Critical state friction angle, $\phi_{\text {crit }}:$ degrees & 32 \\
\hline
\end{tabular}

A dry silica sand (Leighton Buzzard fraction E) with the properties presented in Table 1 was used throughout the test series. The sand was poured to an average relative density, $I_{\mathrm{D}}$, of $90 \%( \pm 3 \%)$ using a sand pouring robot (Madabhushi et al., 2006).

The model tunnel consisted of a rigid brass cylinder and a flexible latex membrane that was sealed to the end caps of the brass cylinder using wire. The cavity between the latex membrane and the brass cylinder was filled with water, and tunnelling-induced volume loss was simulated by extracting the water. This technique allows various volume losses to be simulated within a single experiment. Numerous researches have used this fluid-extraction approach (e.g. Loganathan et al., 2000; Farrell \& Mair, 2012; Marshall et al., 2012; Franza \& Marshall, 2016). During acceleration of the centrifuge, the tunnel pressure was balanced with the vertical soil stresses at the tunnel axis to minimise ground movements surrounding the tunnel (Ritter et al., 2017).

A total of six building models were $3 \mathrm{D}$ printed on a ZCorporation Zprinter350 using Visijet PXL Core powder and Visijet PXL clear binder. Due to the $3 \mathrm{D}$ printing technique, building details (facade openings, strip footings, a

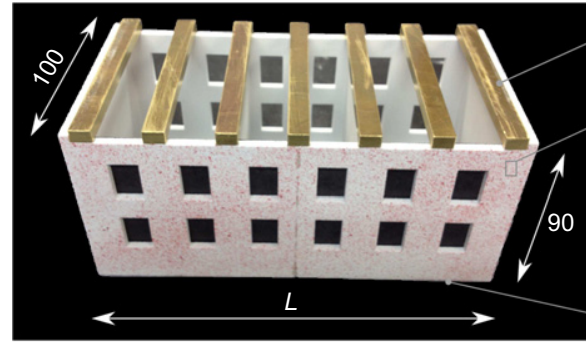

(a)

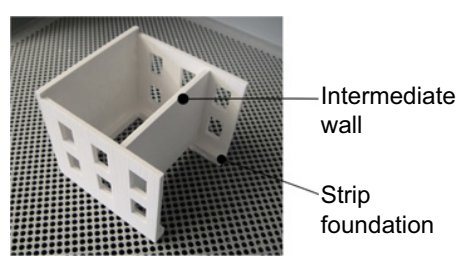

(b)
Dead load bars

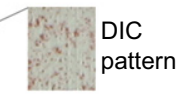

Rough soil-structure interface intere

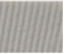

Fig. 4. 3D printed building model (dimensions in mm). DIC, digital image correlation

rough foundation base and intermediate walls) were reproduced at a scale of 1:75, as shown in Fig. 4. In every print job, model beam specimens were printed and subsequently tested in four-point bending. Table 2 summarises the derived 3D printed material properties of the building models. A comparison with typical properties of masonry (Giardina et al., 2015b) indicated that the 3D printed material had a lower density than masonry, a Young's modulus comparable to that of historic masonry and higher flexural strength and ultimate strain. Accordingly, the building cross-sections were adjusted to obtain global bending stiffness, $E I$, and axial stiffness, $E A$, values frequently reported in case studies (e.g. 
Table 2. Material properties of the used 3D printed material; the masonry properties are according to Giardina et al. (2015b)

\begin{tabular}{l|c|l|c|c}
\hline & $\begin{array}{c}\text { Density, } \\
\rho: \mathrm{kg} / \mathrm{m}^{3}\end{array}$ & $\begin{array}{c}\text { Flexural } \\
\text { strength, } \\
f_{\mathrm{t}}: \mathrm{MPa}\end{array}$ & $\begin{array}{c}\text { Young's } \\
\text { modulus, } \\
E: \mathrm{MPa}\end{array}$ & $\begin{array}{c}\text { Ultimate } \\
\text { strain to } \\
\text { failure, } \\
\varepsilon_{\text {ult }}: \%\end{array}$ \\
\hline Test A & 1293 & $1 \cdot 362$ & $893 \cdot 1$ & $0 \cdot 298$ \\
Test B & 1278 & $1 \cdot 311$ & $800 \cdot 6$ & $0 \cdot 357$ \\
Test C & 1261 & $1 \cdot 130$ & $727 \cdot 4$ & $0 \cdot 282$ \\
Test D & 1272 & $0 \cdot 934$ & $516 \cdot 0$ & $0 \cdot 352$ \\
Test E & 1280 & $1 \cdot 139$ & $689 \cdot 9$ & $0 \cdot 309$ \\
Test F & 1247 & $1 \cdot 702$ & $1039 \cdot 2$ & $0 \cdot 246$ \\
Mean & 1272 & $1 \cdot 263$ & $777 \cdot 7$ & $0 \cdot 307$ \\
Masonry* & 1900 & $0 \cdot 1-0 \cdot 9$ & $1000-9000$ & $0 \cdot 05 \dagger$ \\
\hline
\end{tabular}

*According to Giardina et al. (2015a, 2015b).

$\uparrow$ Strain at onset of cracking for brick walls (Burland \& Wroth, 1974).

Mair \& Taylor, 2001; Dimmock \& Mair, 2008; Farrell et al., 2012). Table 3 summarises the building configurations, the building stiffness values in model and prototype scale (which were obtained following Farrell et al. (2012)) and the important dimensionless groups of this soil-structure interaction problem. A reduction of the global building bending stiffness due to facade openings was considered by applying the reduction factors proposed by Melis \& Rodriguez Ortiz (2001) to the $E I$ values for the walls while the $E A$ values ignore facade openings. As can be seen in Fig. 4(a), dead load bars were placed on top of the building models to obtain a constant bearing pressure of $100 \mathrm{kPa}$ beneath the footings transverse to the tunnel.

The structural model was placed on top of the sand model before centrifuge acceleration. Subsequently, the tunnel excavation was performed. Throughout the experiments, images were captured with three digital cameras positioned in front of the poly(methyl methacrylate) (PMMA) window. These images were used to derive displacements of the ground and building model by applying digital image correlation (DIC) using the software GeoPIV (White et al., 2003). Further instrumentation in the form of linear variable differential transformers (LVDTs) and laser displacements sensors enabled evaluation of the image-based measurements and quantification of the boundary effects between the PMMA window and the soil. Further details about the experimental set-up and modelling effects are reported elsewhere (Ritter et al., 2017).

\section{SOIL RESPONSE}

The presence of surface structures alters settlement profiles associated with the tunnelling procedure. However, there is a lack of data quantifying the tunnelling-induced soil movements beneath adjacent buildings. Thus, alteration of the soil response is first explored.

\section{Building geometry effects on vertical soil response}

Vertical soil surface displacements. Surface settlement profiles at a tunnel volume loss $\left(V_{1, \mathrm{t}}\right)$ of $2 \cdot 0 \%$ are given in Fig. 5. The entire set of tests modified the settlement troughs. The structure in test A, which was placed symmetric to the tunnel, substantially reduced the vertical ground movements above the tunnel compared with the greenfield equivalent. A slight reduction in vertical ground settlements above the tunnel was also observed in test B. In contrast, the structure with a building end located above the tunnel (test $\mathrm{C}$ ) caused substantially greater vertical soil displacements in the same area. This localised effect for a tunnel excavated underneath a building end was also observed by Liu et al. (2001) and Bilotta et al. (2017). Contrary to structure A, structures B and $\mathrm{C}$ increased the vertical soil displacements beneath the centre of the building, which was away from the tunnel centre-line.

Figure 5(b) shows that an increase in the amount of openings from $20 \%$ to $40 \%$ of the area of the building facade slightly reduced the modification of the greenfield soil movements underneath the centre of structures $\mathrm{D}$ and $\mathrm{F}$. This is likely caused by the greater opening percentage, which increased flexibility. Structure F also caused substantially greater soil settlements beneath the left-hand building edge, demonstrating that higher flexibility in the hogging region caused increased embedment above the tunnel. By contrast, for structure E, which had $20 \%$ openings but was otherwise similar to test $F$, the reduced curvature of the vertical soil settlement profile beneath the building indicates a less flexible response, which then decreased embedment above the tunnel (Fig. 5(b)). These findings confirm that the amount of window area changes a building's flexibility, which then affects soil displacement. Fig. 5(b) also indicates that the building length directly affected the modification of the vertical surface soil displacements.

Ground loss. Empirical methods to estimate ground movements caused by the tunnelling process are generally based on assumptions about the induced ground loss. In granular soils, shearing causes volume changes of the soil above the tunnel and, for greenfield conditions, the volumes of the settlement troughs vary with depth (Hansmire \& Cording, 1985; Marshall et al., 2012). For shallow tunnels in dense sand, Marshall et al. (2012) reported substantial dilation of the soil body above the tunnel, which reduced the volume of the soil settlement trough, $V_{1, \mathrm{~s}}$, compared with the tunnel volume loss, $V_{1, \mathrm{t}}$.

Table 3. Details of the test series

\begin{tabular}{l|c|c|c|c|c|c|c|c|c|c}
\hline \multirow{2}{*}{ Test } & \multicolumn{9}{|c|}{ Model scale } & \multicolumn{2}{c|}{$\begin{array}{c}\text { Prototype scale* } \\
\text { Dimensionless } \\
\text { groups }\end{array}$} \\
\cline { 2 - 10 } & $e: \mathrm{mm}$ & $L: \mathrm{mm}$ & $H: \mathrm{mm}$ & $O: \%$ & $\begin{array}{c}E A_{\mathrm{m}}: \\
\mathrm{kN} / \mathrm{m}\end{array}$ & $\begin{array}{c}E I_{\mathrm{m}}: \\
\mathrm{kNm} / \mathrm{m}\end{array}$ & $\begin{array}{c}E A_{\mathrm{p}}: \\
\mathrm{kN} / \mathrm{m}\end{array}$ & $\begin{array}{c}E I_{\mathrm{p}}: \\
\mathrm{kNm} / \mathrm{m}\end{array}$ & $e / L$ & $L / H$ \\
\hline $\mathrm{A}$ & 0 & 200 & 90 & 20 & $7 \cdot 5 \times 10^{3}$ & $4 \cdot 0$ & $5 \cdot 3 \times 10^{5}$ & $1 \cdot 5 \times 10^{6}$ & 0 & $2 \cdot 2$ \\
$\mathrm{~B}$ & 160 & 200 & 90 & 20 & $6 \cdot 7 \times 10^{3}$ & $3 \cdot 6$ & $4 \cdot 8 \times 10^{5}$ & $1 \cdot 3 \times 10^{6}$ & $0 \cdot 8$ & $2 \cdot 2$ \\
$\mathrm{C}$ & 100 & 200 & 90 & 20 & $6 \cdot 1 \times 10^{3}$ & $3 \cdot 3$ & $4 \cdot 3 \times 10^{5}$ & $1 \cdot 2 \times 10^{6}$ & $0 \cdot 5$ & $2 \cdot 2$ \\
$\mathrm{D}$ & 160 & 200 & 90 & 40 & $4 \cdot 3 \times 10^{3}$ & $1 \cdot 1$ & $3 \cdot 1 \times 10^{5}$ & $4 \cdot 0 \times 10^{5}$ & $0 \cdot 8$ & $2 \cdot 2$ \\
$\mathrm{E}$ & 130 & 260 & 90 & 20 & $5 \cdot 8 \times 10^{3}$ & $3 \cdot 1$ & $4 \cdot 1 \times 10^{5}$ & $1 \cdot 1 \times 10^{6}$ & $0 \cdot 5$ & $2 \cdot 9$ \\
$\mathrm{~F}$ & 130 & 260 & 90 & 40 & $8 \cdot 7 \times 10^{3}$ & $2 \cdot 2$ & $6 \cdot 2 \times 10^{5}$ & $8 \cdot 1 \times 10^{5}$ & $0 \cdot 5$ & $2 \cdot 9$ \\
\hline
\end{tabular}

*The used scale factor (i.e. $N=71 \cdot 6$ ) was obtained at mid-height of building models. 


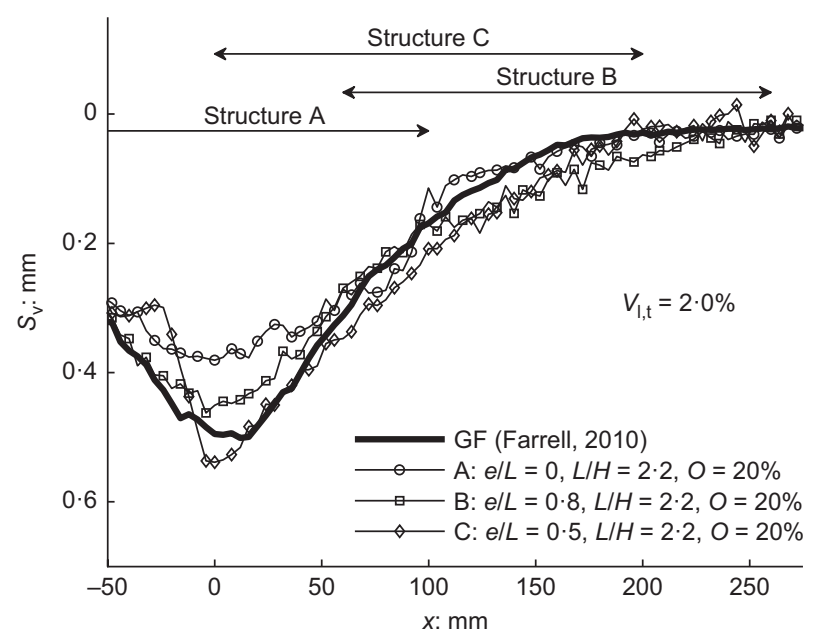

(a)

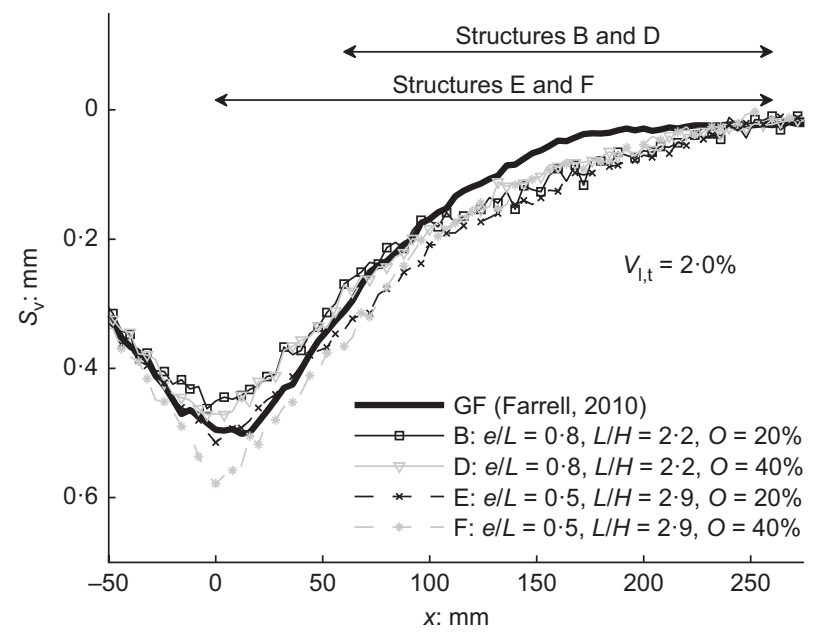

(b)

Fig. 5. Building effects on vertical surface soil displacements at a tunnel volume loss of $2 \cdot 0 \%$ : (a) effect of building eccentricity (constant $L$ and $O$ ); (b) effect of building length and facade openings

Figure 6 was obtained by numerical integration of the vertical soil displacement profiles and indicates the building effects on $V_{1, \mathrm{~s}}$. At the soil surface (Figs 6(a) and 6(b)) and at half the tunnel depth $\left(z / z_{\mathrm{t}}=0 \cdot 5\right)$ (Fig. 6(c)), an overall dilative behaviour was observed. Particularly, as $V_{1, \mathrm{t}}$ increased, the rate of increase of $V_{1, \mathrm{~s}}$ decreased.

Figure 6(a) shows that the building position influenced the ground loss. While the values of $V_{1, \mathrm{~s}}$ below buildings placed eccentric to the tunnel (tests $\mathrm{B}$ and $\mathrm{C}$ ) were in good agreement with the greenfield $V_{1, \mathrm{~s}}$, an identical building model positioned at zero eccentricity (test $\mathrm{A}$ ) resulted in a notably lower value of $V_{1, \mathrm{~s}}$ above $V_{1, \mathrm{t}}=1 \cdot 5 \%$ (Fig. 6(a)). For long buildings (tests $\mathrm{E}$ and $\mathrm{F}$ ), the surface ground loss was greater than for the greenfield case (Fig. 6(b)). An increase in openings from $20 \%$ to $40 \%$ showed a minor influence on $V_{1, \mathrm{~s}}$. In contrast, at the subsurface, all the building models lowered $V_{1, \mathrm{~s}}$ similarly when compared with the greenfield values (Fig. 6(c)).

The effect of building weight contributes to ground loss results. As reported by Franzius et al. (2004), a building surcharge increases the mean effective stresses in the soil body, which then leads to greater soil stiffness and strength. Consequently, the ground movements surrounding a tunnel reduce, as is evident in Fig. 7. This lower magnitude of soil displacements above the tunnel crown explains the lower value of $V_{1, \mathrm{~s}}$ at half the tunnel depth $\left(z / z_{\mathrm{t}}=0 \cdot 5\right)$ shown in

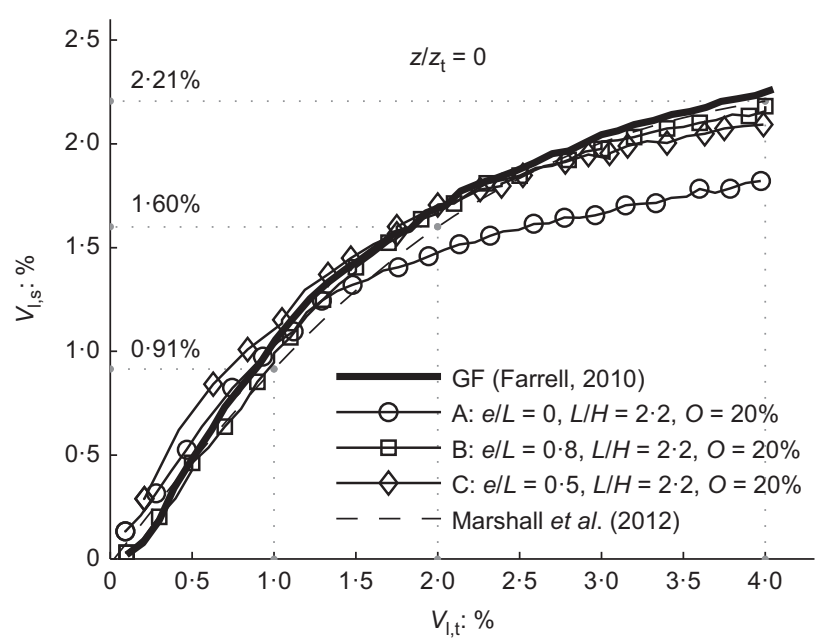

(a)

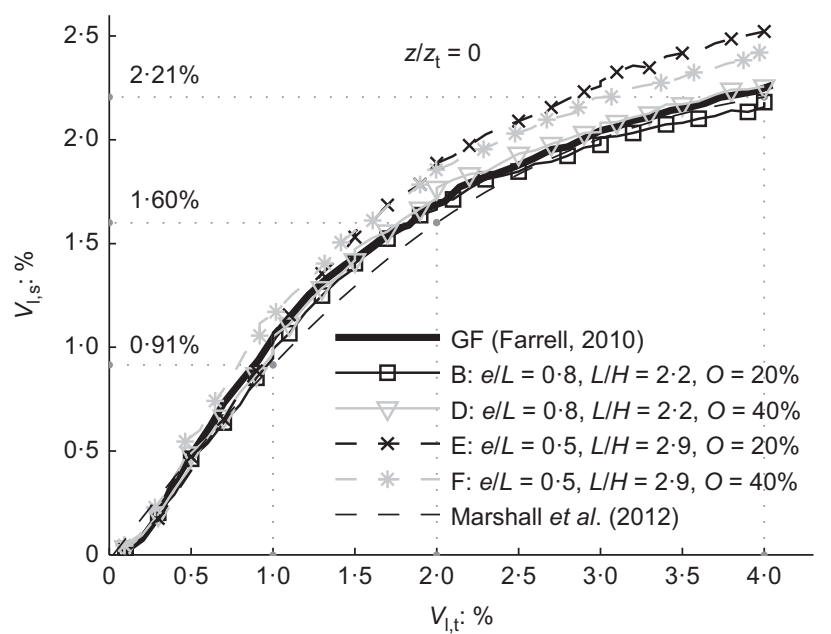

(b)

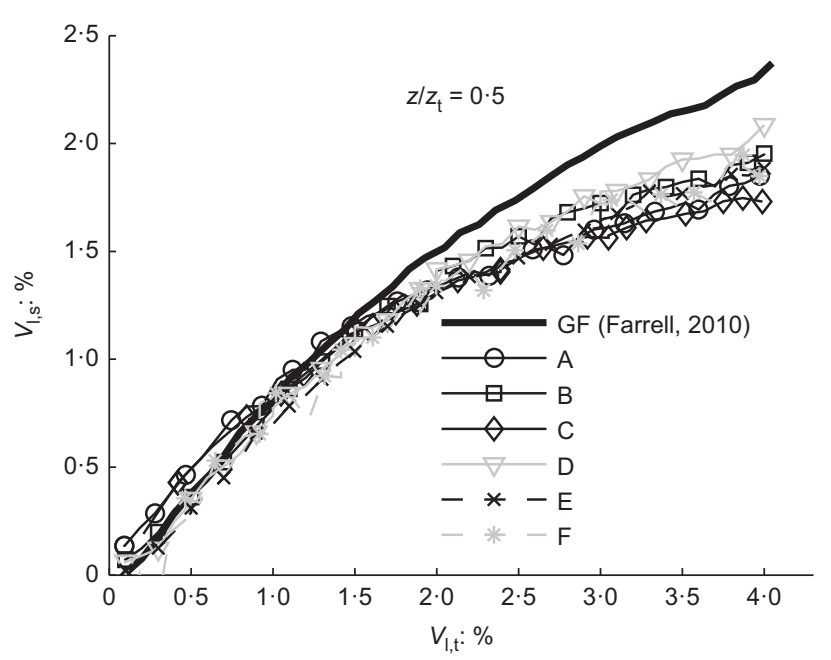

(c)

Fig. 6. Soil volume loss, $V_{1, s}$, plotted against tunnel volume loss, $V_{1, t}$ : (a) effect of building eccentricity (constant $L$ and $O$ ); (b) effect of building length and facade openings; (c) subsurface soil volume loss at $z / z_{\mathrm{t}}=0.5$

Fig. 6(c). The pivotal role of the building weight in this soilstructure interaction problem was also pointed out by Giardina et al. (2015a) and Bilotta et al. (2017).

The volumetric soil behaviour above the tunnel was further clarified by the observed engineering shear strains and volumetric strains (Figs 8 and 9). Fig. 8(a) shows that 

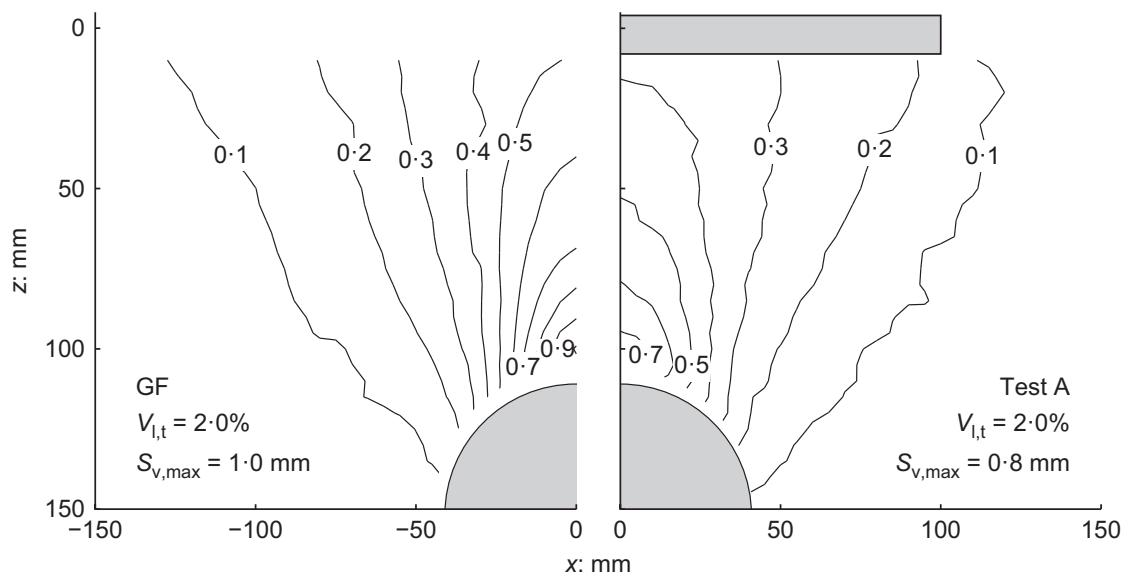

(a)

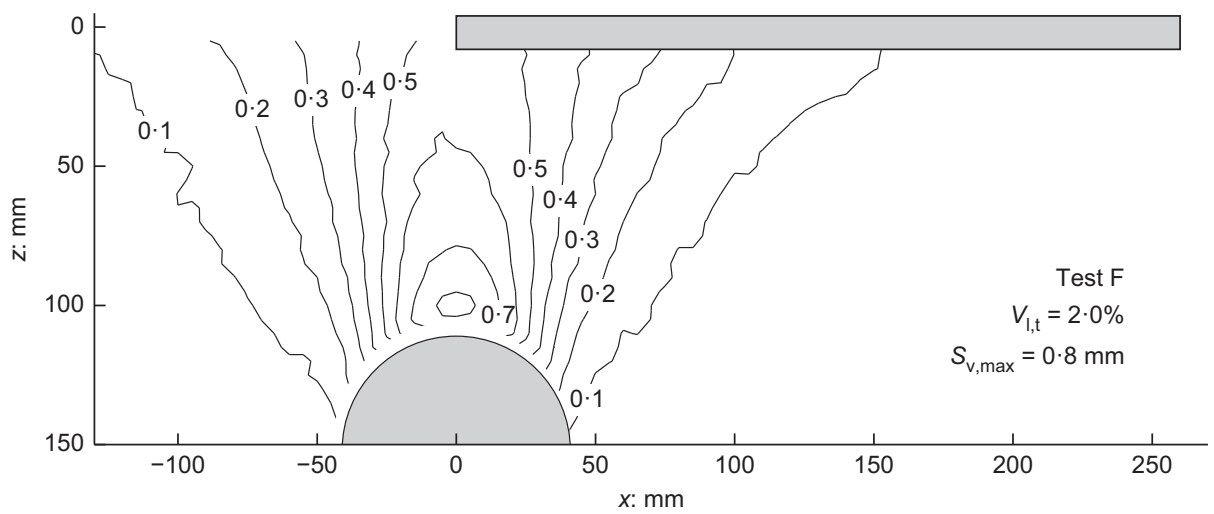

(b)

Fig. 7. Vertical soil displacements at a tunnel volume loss of 2.0\%: (a) greenfield test (Farrell, 2010) and test A (building symmetric to tunnel); (b) test $\mathbf{F}$ (building asymmetric to tunnel)

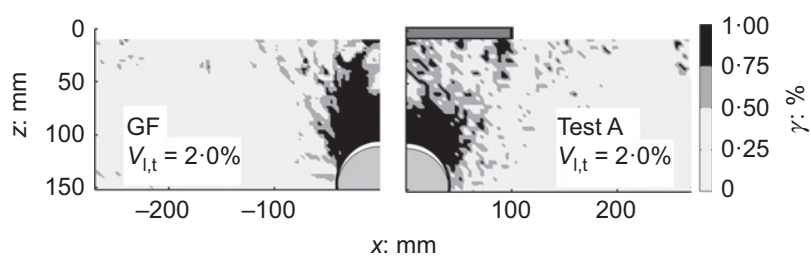

(a)

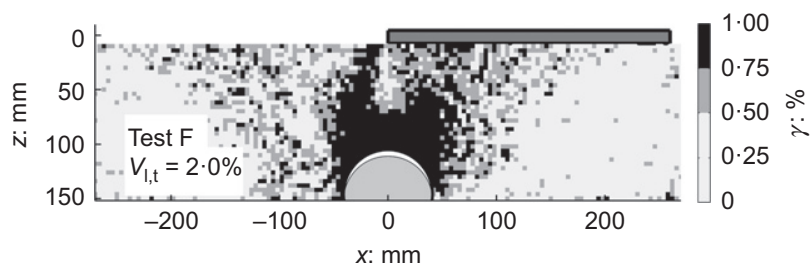

(b)

Fig. 8. Engineering shear strains at a tunnel volume loss of $2 \cdot 0 \%$ : (a) greenfield test and test $\mathrm{A}$ (building symmetric to tunnel); (b) test $\mathrm{F}$ (building asymmetric to tunnel)

building load reduced the amount of shear strains compared with the greenfield scenario, and the soil beneath the building of test A showed less dilation (negative $\varepsilon_{\mathrm{vol}}$ in Fig. 9(a)).

The influence of surface structures on soil shear strains was confirmed by the asymmetric shear strain contours monitored for buildings placed asymmetric to the tunnel (Fig. 8(b)). The building seems to have a negligible effect on the shear strains above the left-hand tunnel shoulder,

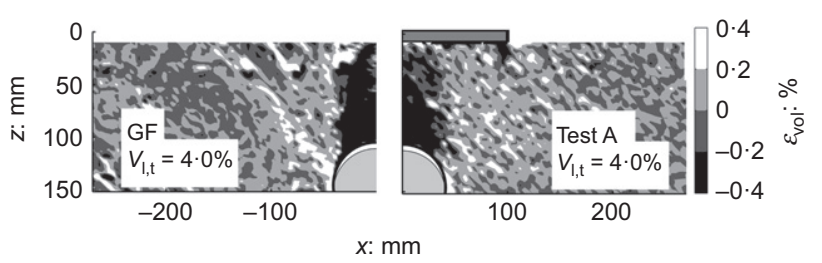

(a)

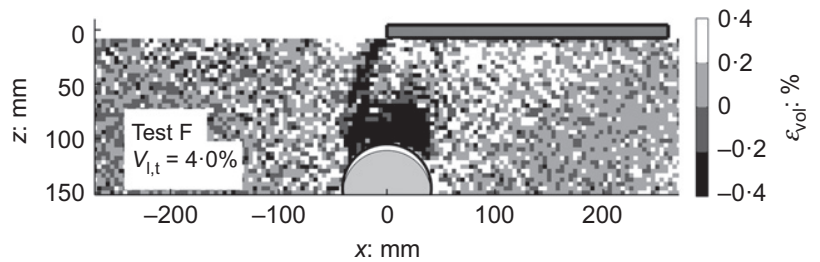

(b)

Fig. 9. Volumetric strains at a tunnel volume loss of $4 \cdot 0 \%\left(\varepsilon_{\mathrm{vol}}<0\right.$ indicates dilation): (a) greenfield test and test $\mathbf{A}$ (building symmetric to tunnel); (b) test $\mathrm{F}$ (building asymmetric to tunnel)

showing shear strains similar to the greenfield case shown in Fig. 8(a). However, the structure reduced the shear strains above the right-hand tunnel shoulder, as shown in Fig. 8(b). A considerable amount of volumetric contraction was measured beneath the building (Fig. 9(b)), which confirms the increase in $V_{1, \mathrm{~s}}$ at $z / z_{\mathrm{t}}=0$ for tests $\mathrm{E}$ and $\mathrm{F}$.

Although the building load, position and length clearly influenced the volumetric behaviour of the soil, and thus the 
tunnelling-induced ground loss, all tests showed rather similar values of $V_{1, \mathrm{~s}}$ for practical volume loss (i.e. $\left.V_{1, \mathrm{~s}}<1 \cdot 5 \%\right)$.

Settlement trough width. The settlement trough width is widely used as an input parameter when empirically predicting tunnelling-induced ground movements. Therefore, the influence of building features on the width of vertical settlement profiles was explored.

Modified Gaussian curves were fitted to the vertical soil displacements because their additional degree of freedom provides a better fit to settlement profiles in drained soil than Gaussian curves (Vorster, 2002; Marshall et al., 2012). For structures located at an offset from the tunnel (i.e. tests $\mathrm{B}$ to F), asymmetric settlement troughs were obtained (Fig. 5) and thus the curve fitting was carried out for the right-hand side only.

To quantify the trough width of the modified Gaussian curves, the framework proposed by Marshall et al. (2012) was adopted. Therefore, the trough width parameter, $K^{*}$, for modified Gaussian curves was calculated, which is similar to estimating the more traditional trough width, $K$, for Gaussian curves. To estimate $K^{*}$, the parameter $x^{*}$, which is the offset from the tunnel centre-line where vertical surface soil displacement $S_{\mathrm{v}}=0.606 S_{\mathrm{v}, \max }$, was first determined. This parameter $\left(x^{*}\right)$ is similar to the inflection point, $i$, of a Gaussian curve because $S_{\mathrm{v}}(i)=0 \cdot 606 S_{\mathrm{v}, \max }$. $K^{*}$ was subsequently obtained for different soil depths by dividing $x^{*}$ by the depth to the tunnel axis (i.e. $z_{\mathrm{t}}-z$ ).

Figure 10(a) shows the effect of different building positions on the surface trough width parameter, $K_{\mathrm{s}}^{*}$. For all the tests, the buildings widened the transverse surface soil settlement troughs beneath them. Buildings placed closer to the tunnel (test A) caused the greatest $K_{\mathrm{s}}^{*}$ values, while the trough width became narrower as $e / L$ increased.

Figure 10(b) shows the relationships between building length, area of facade openings and $K_{s}^{*}$. For the shorter buildings $(L / H=2 \cdot 2)$, an increase in openings from $20 \%$ to $40 \%$ had little effect on $K_{\mathrm{s}}^{*}$. However, for the longer buildings $(L / H=2 \cdot 9)$, doubling the window area significantly narrowed the settlement trough. In this case, the increased flexibility caused the settlement profile to deviate less from the greenfield equivalent. A similar effect was not observed for the shorter structure $(L / H=2 \cdot 2)$ because test $\mathrm{D}$ performed rather rigidly despite having an openings area of $40 \%$. Clearly, and as expected, the building position, length and area of openings need to be considered in combination. The observed widening of the settlement profiles due to an adjacent structure is consistent with field data (e.g. Frischmann et al., 1994; Lu et al., 2001; Viggiani \& Standing, 2001), although these investigations were based on facade monitoring points.

Although $x^{*}$ and $K^{*}$ provide a valuable approach to investigate the settlement trough width, these parameters are less suitable to estimate hogging and sagging modes of displacement profiles, which are defined by the inflection point of the associated settlement trough. The partitioning between hogging and sagging is particularly important for building damage assessment, for which Mair et al. (1996) proposed to separate buildings at the inflection point. Therefore, Fig. 11 provides the variation of the inflection point, $i_{\mathrm{mG}, \mathrm{s}}$, of the modified Gaussian curves fitted to the surface soil settlements. As expected, the data in Fig. 11 indicate similar trough width trends as Fig. 10, but the figure emphasises the fact that the soil-structure interaction has a significant impact on the greenfield inflection point. This outcome implies that treating a building separately either side of the assumed greenfield inflection point might result in

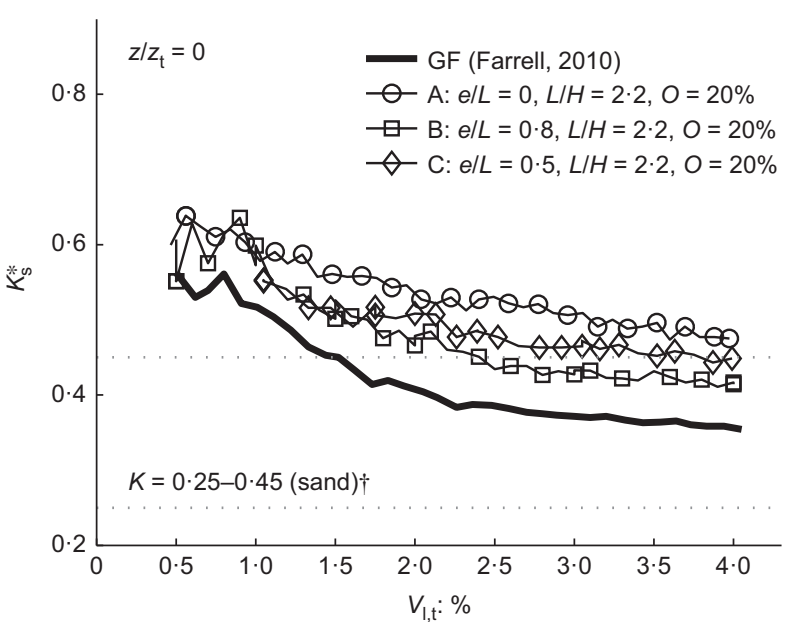

(a)

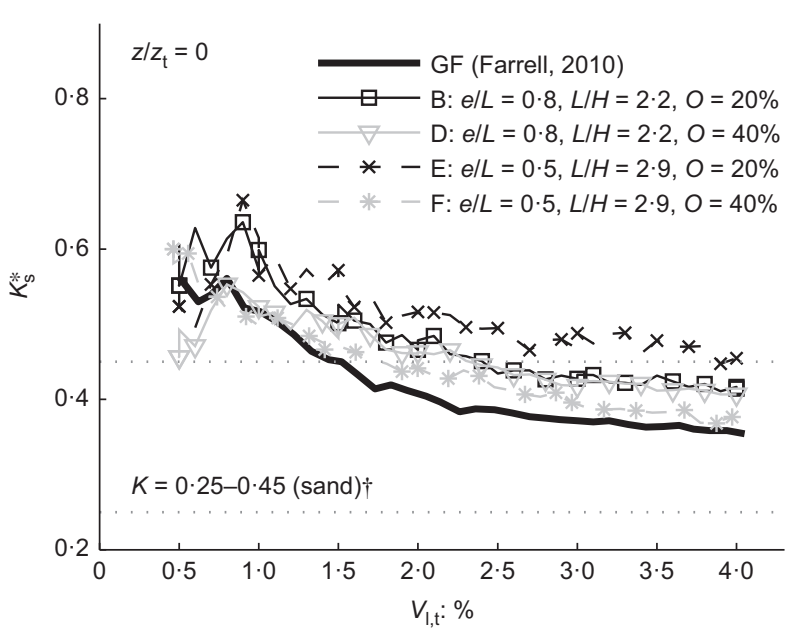

(b)

Fig. 10. Surface trough width parameter, $K_{\mathrm{s}}^{*}$, plotted against tunnel volume loss, $V_{1, t}$ (a) effect of building eccentricity (constant $L$ and $O$ ); (b) effect of building length and facade openings. $\uparrow$ Mair \& Taylor (1997)

substantial uncertainty when predicting building performance to tunnelling subsidence.

\section{Building geometry effects on horizontal soil response}

The focus of the paper thus far has been the vertical soil response, but the effect of buildings on horizontal ground movements is also important for the assessment of both surface and subsurface structures.

Horizontal soil surface displacements. Figure 12 presents the horizontal surface ground movements that complement the vertical ground movement profiles given in Fig. 5. In all the tests, the building models substantially restricted the horizontal ground movements beneath them. Fig. 12(a) indicates that the building-to-tunnel position had only a minor influence on the restraining effect of the buildings on the horizontal soil movements. Likewise, Fig. 12(b) shows that this restraint was also observed for buildings with different lengths and facade openings. It follows that the analysed building variations had a relatively small effect on the axial building stiffness and shear failure was not observed at the soil-structure interface.

The horizontal ground movements beyond the edge of the surface structures were also affected by the presence of the 


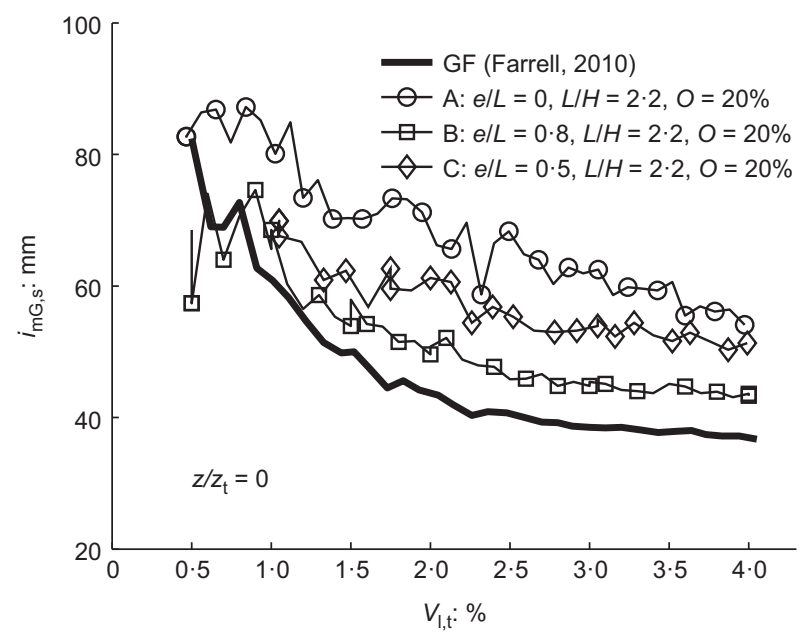

(a)

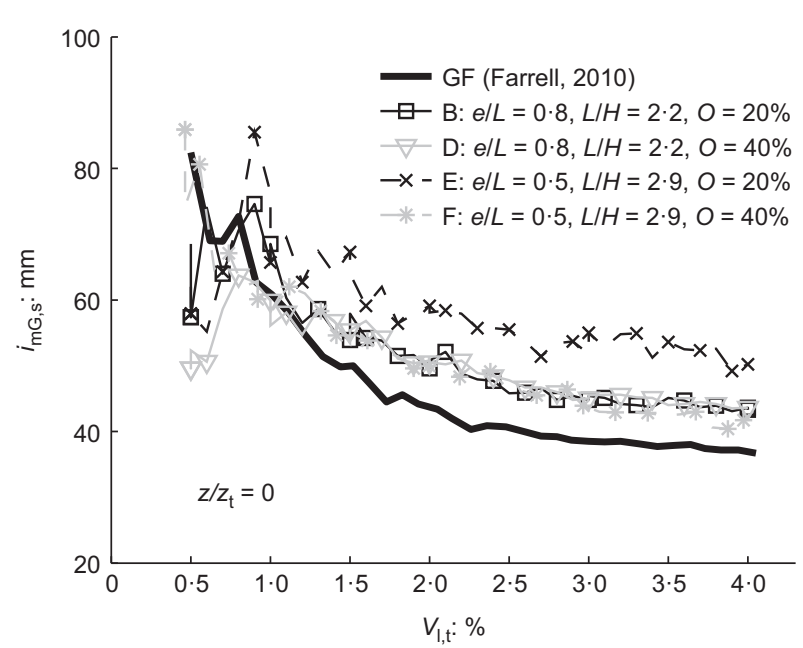

(b)

Fig. 11. Inflection points of the modified Gaussian curves fitted to surface soil settlements: (a) effect of building eccentricity (constant $L$ and $O$ ); (b) effect of building length and facade openings

buildings. In Fig. 12(b) this is particularly evident to the left of the structures B and D, until the greenfield displacements were again restored at a horizontal distance of approximately $30 \mathrm{~mm}$ from the left-hand building edge. Similar findings for building effects on horizontal ground movements were reported by Potts \& Addenbrooke (1997).

Horizontal soil subsurface displacements. Figure 13 shows the horizontal soil displacement with depth at an offset from the tunnel centre-line of $x=70 \mathrm{~mm}$. For all the soil-structure interaction tests, buildings were present at that $x$ position. Close to the soil surface, the restraining effect of the soilstructure interaction is clearly visible in Fig. 13. However, at a soil depth between $z / z_{\mathrm{t}}$ values of $0 \cdot 13$ and $0 \cdot 26$, the horizontal ground movements were in fair agreement with the greenfield displacements (Standing, 2001; Farrell, 2010). These findings are the results of the rough soil-structure interface and indicate that the restraining effect of the building on the horizontal soil movements is a rather shallow mechanism; slippage between the foundation and the soil surface was not observed. At $z / z_{\mathrm{t}}>0 \cdot 26$, the slightly lower horizontal ground displacements measured in the soilstructure tests compared with the greenfield case can be attributed to the greater soil stiffness, as mentioned earlier.

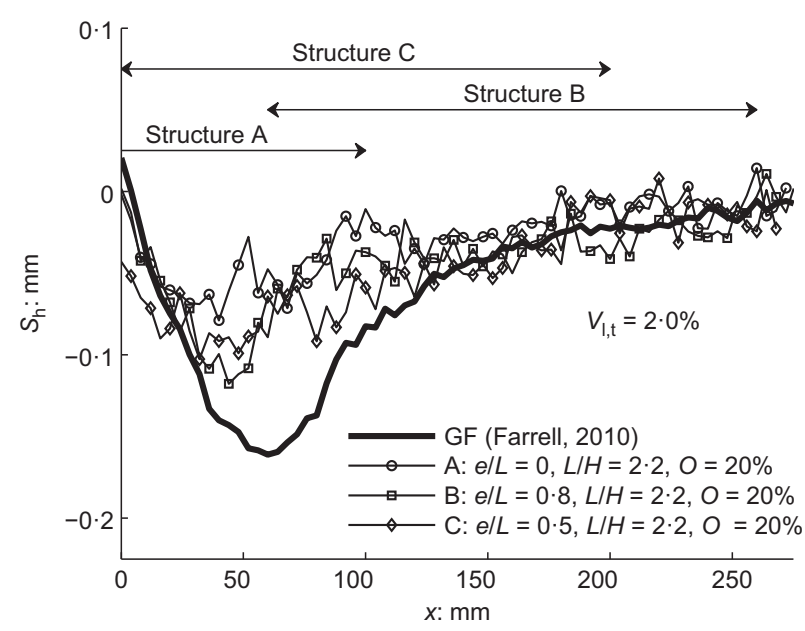

(a)
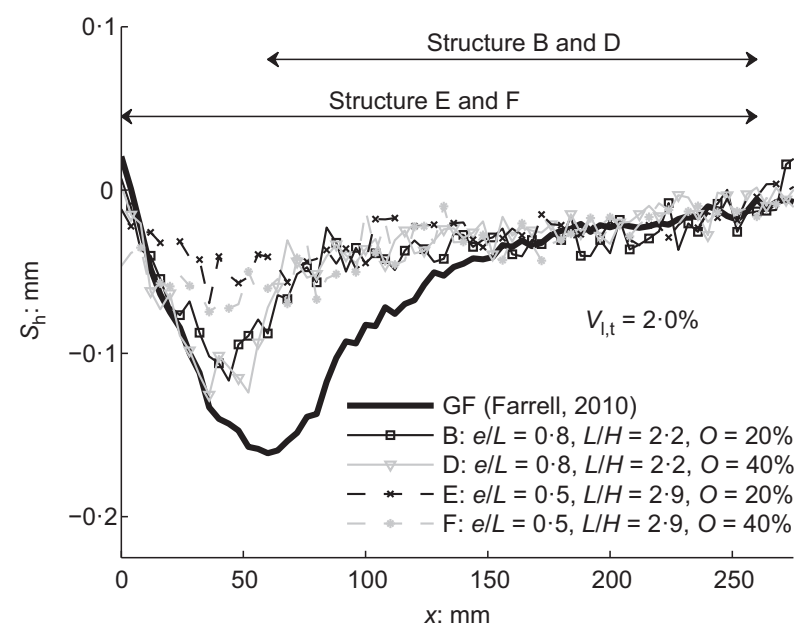

(b)

Fig. 12. Effect of soil-structure interaction on horizontal surface soil displacements at tunnel volume loss of $2 \cdot 0 \%$ : (a) effect of building eccentricity (constant $L$ and $O$ ); (b) effect of building length and facade openings

The variation of horizontal soil displacements with depth was unaffected by the differing building features.

\section{BUILDING RESPONSE}

Having discussed the impact of buildings on tunnelling-induced settlements, this section describes the building performance using widely accepted building deformation parameters, namely the deflection ratio and horizontal strain. The soil-structure interaction effects are quantified in terms of modification factors.

\section{Effects of building geometry on deflection ratio}

Figure 14 shows the variation of the deflection ratios with volume loss in sagging and hogging. The building subdivision into hogging and sagging was carried out using the inflection point associated with the modified Gaussian curves fitted to the vertical surface soil displacement profiles (Fig. 11). To reduce the GeoPIV measurement noise, the vertical displacements at the base of the surface structures were smoothed by fifth-order polynomials. This curve-fitting approach provided a significantly better fit than the modified Gaussian curves, which tended to overestimate the building deflections. Subsequently, for structures spanning the 


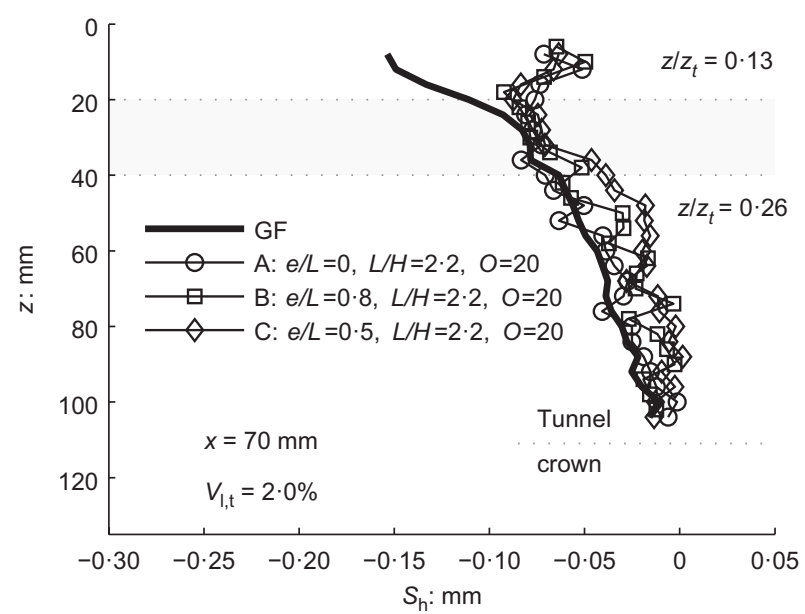

(a)

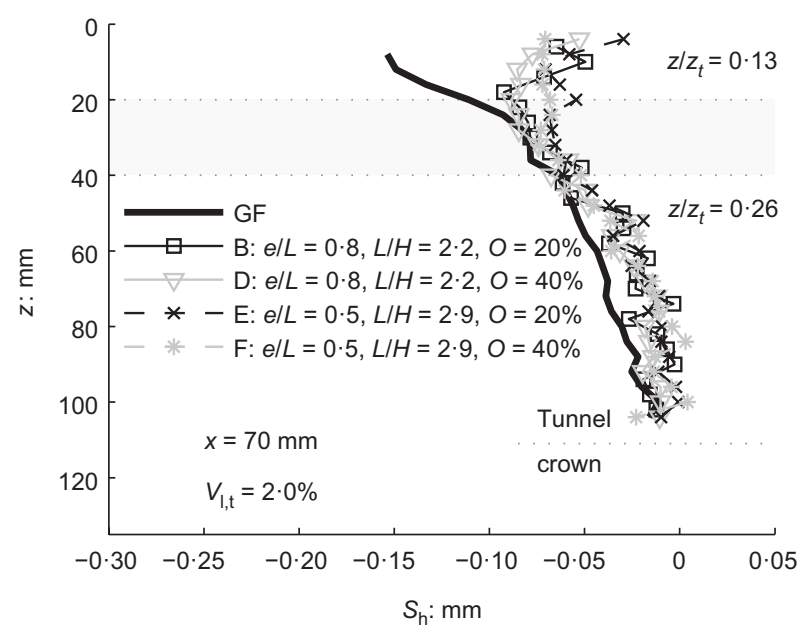

(b)

Fig. 13. Horizontal soil displacement, $S_{\mathrm{h}}$, profiles at $x=70 \mathrm{~mm}$ and a tunnel volume loss, $V_{1, t}$, of $2 \cdot 0 \%$ : (a) effect of building eccentricity (constant $L$ and $O$ ); (b) effect of building length and facade openings

hogging/sagging transition zone, the deflection ratios were estimated individually for both the hogging and sagging mode. The observed scatter in $D R_{\text {sag }}$ for tests $\mathrm{C}, \mathrm{E}$ and $\mathrm{F}$ was caused by small sagging regions and small measurements of building distortion.

The adopted hogging/sagging subdivision implies that the building-to-tunnel position plays a key role, which can also be observed in Fig. 14. The building placed at zero eccentricity (test A) caused a positive deflection ratio $\left(D R_{\mathrm{sag}}\right)$ while an equal building positioned at $e / L=0 \cdot 8$ (test $\mathrm{B}$ ) showed a hogging mode of deflection $\left(D R_{\mathrm{hog}}\right)$ and is thus likely to be at greater risk of building damage (Mair et al., 1996). On the other hand, test $C$, in which the building was spanning the hogging/sagging region, showed a hogging and sagging response and caused an even greater $D R_{\text {hog }}$ than that in test B. This indicates that structures positioned in the hogging/sagging transition zone of the tunnelling-induced settlement trough are potentially more vulnerable to building damage.

As the building length and the facade opening percentage increased, greater deflection ratios were measured (Fig. 14). This is particularly evident for the hogging mode of deflection and can be explained by a more flexible building response. For test $\mathrm{D}$, the increase in window area nearly doubled the $D R_{\text {hog }}$ value of test $\mathrm{B}$, in which the building was of identical length and eccentricity. Likewise, $D R_{\mathrm{hog}}$

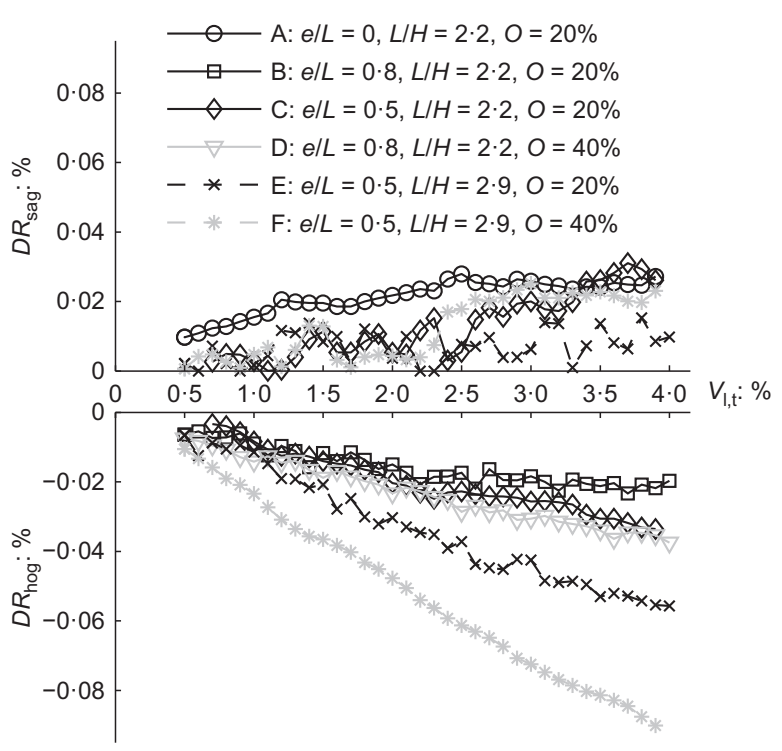

Fig. 14. Deflection ratios of the soil-structure interaction tests

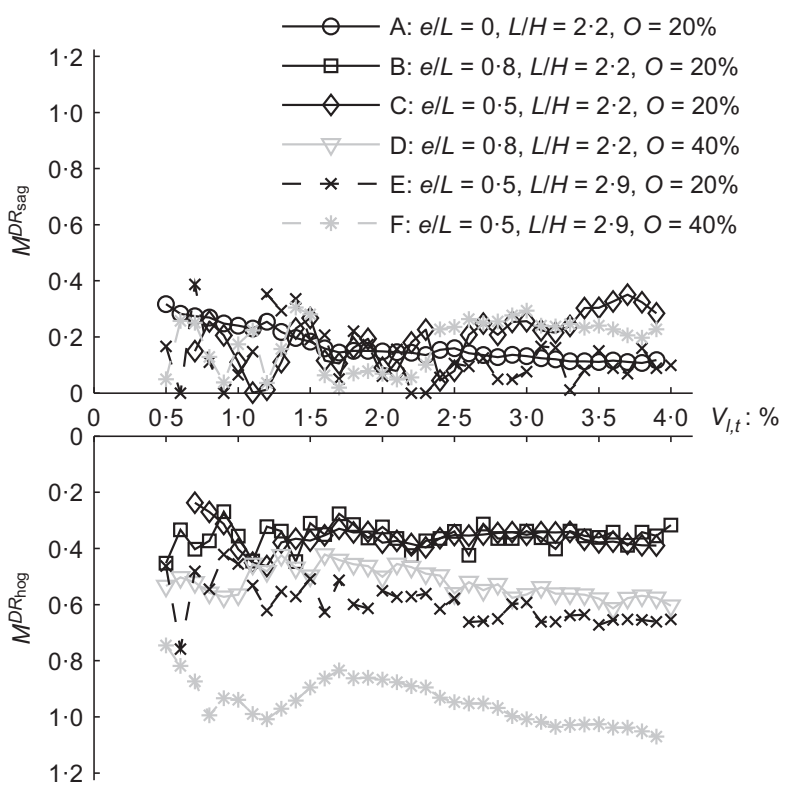

Fig. 15. Modification factors for deflection ratios

substantially increased for the long structure with an openings area of $40 \%$ (test F) compared with the equally long structure with $20 \%$ openings (test E).

With respect to the building length, the magnitude of $D R_{\text {hog }}$ nearly doubled when the building length increased from $L / H=2 \cdot 2$ to $L / H=2 \cdot 9$. This can be clearly seen when comparing the $D R_{\text {hog }}$ trends of test $\mathrm{E}$ to tests $\mathrm{B}$ and $\mathrm{C}$ in Fig. 14. Specifically, the comparison between tests $\mathrm{D}$ and $\mathrm{F}$ highlights the effect of the building length on $D R_{\text {hog }}$.

In Fig. 15, the data from Fig. 14 are compared with the associated greenfield deflection ratios, which were obtained by using the greenfield soil settlement profiles and taking the corresponding building-to-tunnel position into account. The obtained modification factors for the deflection ratio in sagging, $M^{D R_{\text {sag }}}$, and hogging, $M^{D R_{\text {hog }}}$, were generally below unity. This indicates that the building deflections were lower than the greenfield equivalent.

The modification factors vary with building features. While minor differences were obtained for $M^{D R_{\text {sag }}}$, the 


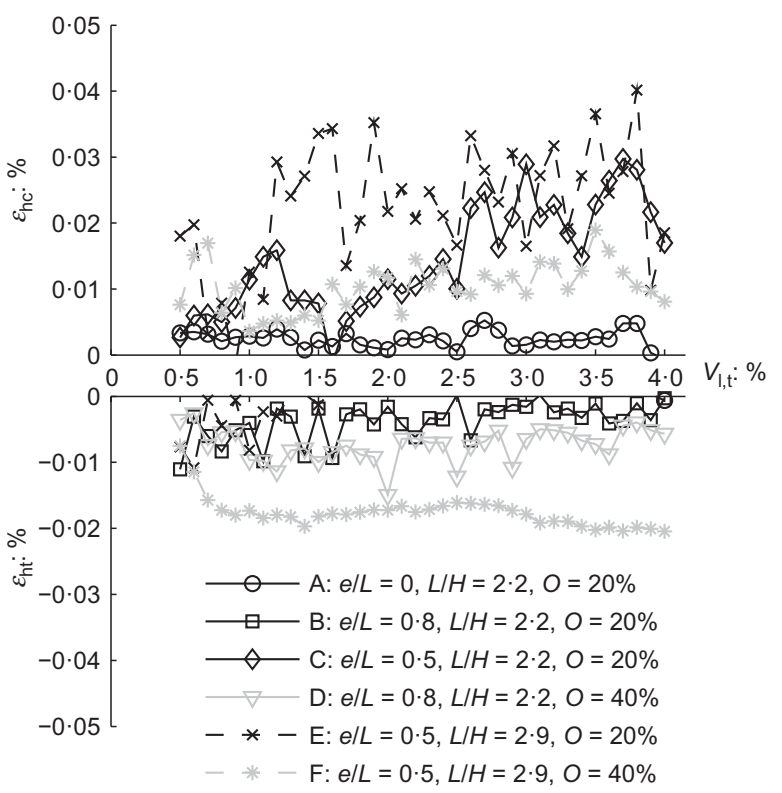

Fig. 16. Average horizontal strain at base of buildings (tension is negative)

different building characteristics substantially altered $M^{D R_{\mathrm{hog}}}$. Interestingly, a change in building position from $e / L=0.8$ (test B) to $e / L=0 \cdot 5$ (test C) did not affect $M^{D R_{\text {hog }}}$ (Fig. 15). Conversely, an increase in the building length and facade openings caused greater values of $M^{D R_{\text {hog }}}$ and, for the long structure of test $\mathrm{F}$ with $40 \%$ of facade openings, hogging deflections similar to the greenfield case were observed (i.e. $M^{D R_{\mathrm{hog}}}=1$ ). Notably, these high $M^{D R_{\mathrm{hog}}}$ values for test $\mathrm{F}$ occurred at tunnel volume losses below $1 \cdot 0 \%$. The remaining tests showed building distortions lower than about $65 \%$ of the greenfield values for the entire range of tunnel volume loss studied.

\section{Effects of building geometry on horizontal strain}

Horizontal building strains were determined from the slope of a linear curve fitted to the horizontal displacements of the sagging and hogging regions of the building. The horizontal displacements were obtained close to the base of the building and the hogging/sagging partitioning was again based on $i_{\text {mG,s. }}$ Fig. 16 shows the obtained horizontal strains in compression, $\varepsilon_{\mathrm{hc}}$, and tension, $\varepsilon_{\mathrm{ht}}$. In particular, it can be seen that $\varepsilon_{\text {hc }}$ was affected by small sagging regions that caused substantial scatter when deriving $\varepsilon_{\mathrm{hc}}$.

The data in Fig. 16 show only compressive strains for structures $\mathrm{C}$ and $\mathrm{E}$. It is likely that this result is related to a rigid-body rotation of the building towards the tunnel, which then caused an embedment of the left-hand building corner (Fig. 5). Consequently, the horizontal movement of the structure was substantially constrained above the tunnel and compressive horizontal strains were measured. For test A, which was predominantly placed in the sagging zone, compressive strains were derived while an identical building placed at $e / L=0 \cdot 8$ (test B) showed tensile strains. Slightly greater tensile strains were monitored for the building of test $\mathrm{D}$, which had the same length and location as the structure in test B but $40 \%$ of openings. The greatest tensile strains were, however, measured for test $\mathrm{F}$, which is identical to the $D R_{\mathrm{hog}}$ results. The increase in building length and facade openings caused substantially greater horizontal building tensile strains. Nevertheless, the obtained horizontal building strains were in 'category 0' (negligible) when adopting the

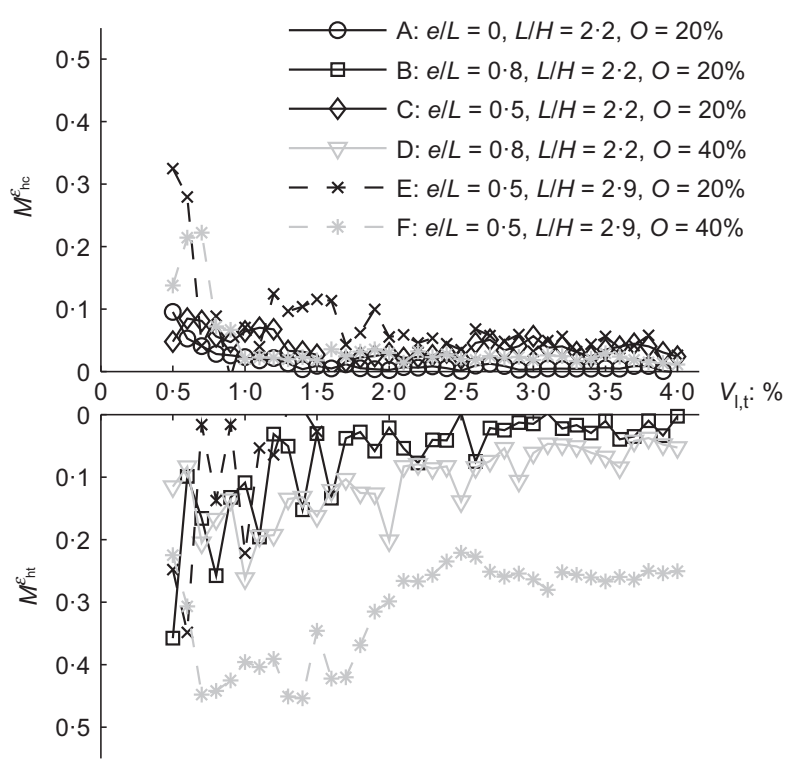

Fig. 17. Modification factors for horizontal strains

damage category chart defined by Burland (1995) and strains caused by the building deflection are neglected.

Figure 17 shows the modification factors for the horizontal strain in compression $M^{\varepsilon_{\mathrm{hc}}}$ and tension $M^{\varepsilon_{\mathrm{ht}}}$. In all the tests, the compressive strains were generally below $10 \%$ of the corresponding average horizontal greenfield strains, which were obtained following Mair et al. (1996). The greater values at a $V_{1, \mathrm{t}}$ value of about $0 \cdot 5 \%$ are most likely due to noise in the GeoPIV data. In tension, considerably greater modification factors were observed for test $\mathrm{F}$, with average horizontal building tensile strains of about $40 \%$ compared with the greenfield case. The results of test $F$ were followed by test $\mathrm{D}$, which indicates that buildings with a larger window area might be more susceptible to horizontal tensile strains.

\section{CONCLUSIONS}

Experimental data of a centrifuge test series on building response to a shallow tunnel excavation in dry, dense sand have been presented. Building characteristics (e.g. a rough soil-structure interface, strip footings, intermediate walls and facade openings) were replicated by $3 \mathrm{D}$ prints of building models. The following conclusions can be drawn from the experimental results.

- Vertical soil surface displacements exceeding the greenfield values were observed when the tunnel excavation passed directly underneath a building corner. Similar results were reported by Liu et al. (2001) and Bilotta et al. (2017). This phenomenon reduced for the stiffer longer building tested.

- A structure in close proximity to the tunnel excavation changed the volumetric behaviour of the soil above the tunnel and the tunnelling-induced displacement field. Similar building weight effects were also identified previously (Franzius et al., 2004; Giardina et al., 2015a, 2015b; Bilotta et al., 2017). Consequently, the observed surface and subsurface volume losses were affected by nearby structures. Long structures caused volumetric soil contraction beneath them and the surface volume loss values were greater than those of the greenfield case. Structures placed symmetrically to the tunnel reduced the surface volume loss while the area of facade openings showed only a minor influence. 
- The presence of buildings widened the vertical soil settlement trough compared with the greenfield case. The widest trough was obtained for a structure with zero eccentricity and the trough became narrower as the distance between the building and the tunnel increased. An increase in flexibility of the building, caused by a greater building length and/or a greater area of facade openings, reduced this widening effect. Field data of building displacement profiles above tunnels confirm these findings (Frischmann et al., 1994; Lu et al., 2001; Viggiani \& Standing, 2001).

- The absolute and differential horizontal ground displacements just beneath the surface structures were significantly restrained by the buildings. However, the horizontal greenfield soil movements were recovered at a soil depth between $z / z_{\mathrm{t}}=0 \cdot 13$ and $0 \cdot 26$, which is in fair agreement with the findings of Standing (2001) and Farrell (2010). Changes in the relative position of the building to the tunnel, the building length and the facade openings had little effect on the reduction of horizontal ground movements.

- Building stiffness plays a key role in the building's response to tunnel excavation and predictions based on greenfield assumptions are, in general, overly conservative. However, the centrifuge experiments showed that the building-to-tunnel position, the building length and the amount of facade openings are also important factors. In the sagging region, the measured building distortions were below $40 \%$ of the greenfield equivalent. The building characteristics had a minor influence on the sagging deflections. However, in hogging, significantly greater building distortions were observed with increases in building length and the percentage of facade openings. For a tunnel passing beneath the building corner of a long flexible structure with $40 \%$ openings, building deflections equal to the greenfield case were obtained, even at tunnel volume losses below $1 \cdot 0 \%$.

- Structures located in the hogging and sagging regions of the tunnelling-induced settlement profile were more vulnerable (in terms of the deflection ratio) than buildings of identical length positioned entirely in sagging or hogging.

- For most of the investigated cases, the horizontal strains induced in the structures were negligible, as has been observed in the field (Mair, 2013) and in previous centrifuge experiments (Farrell \& Mair, 2012). However, for structures with a considerable area of openings, average horizontal building strains of up to $40 \%$ of the greenfield equivalent were measured. This indicates that horizontal strains, although considerably less than those predicted using greenfield conditions, might be appreciable in flexible structures.

The centrifuge modelling carried out enabled these new insights into the mechanism of tunnelling-induced ground displacements on surface structures. A limitation of this work is that the $3 \mathrm{D}$ effects of tunnel advancement, which might cause an adverse torsional response of the building, were not studied. The obtained data also provide important new information with which to evaluate the currently available design procedures that are based on relative stiffness expressions. In addition, the results of this study provide useful benchmark data for computational modelling.

\section{ACKNOWLEDGEMENTS}

The authors thank the Engineering and Physical Sciences Research Council (grant EP/KP018221/1) and Crossrail for financially supporting this research. The technicians of the
Schofield Centre are acknowledged for their contribution when running the centrifuge test series. Special thanks go to Dr Ruaidhri P. Farrell for sharing greenfield data. The related research data are available at https://doi.org/10.17863/ CAM.10554.

$\begin{aligned} & \text { NOTATION } \\ & B \text { building width } \\ & C \text { cover } \\ & D \text { tunnel diameter } \\ & D R \text { deflection ratio } \\ & E \text { Young's modulus } \\ & E A \text { axial stiffness } \\ & E I \text { bending stiffness } \\ & e \text { building eccentricity } \\ & e_{\text {max }} \text { maximum voids ratio } \\ & e_{\mathrm{min}} \text { minimum voids ratio } \\ & f_{\mathrm{t}} \text { flexural strength } \\ & G_{\mathrm{s}} \text { specific gravity } \\ & g \text { Earth's gravity field } \\ & H \text { building height } \\ & I_{D} \text { relative density } \\ & i \text { point of inflection } \\ & K \text { trough width } \\ & K^{*} \text { trough width parameter } \\ & K_{\mathrm{S}}^{*} \text { surface trough width parameter } \\ & L \text { building length } \\ & M_{\mathrm{g}} \text { modification factor } \\ & O \text { facade openings } \\ & S_{\mathrm{h}} \text { horizontal soil displacement } \\ & S_{\mathrm{v}} \text { vertical soil displacement } \\ & V_{1, \mathrm{~s}} \text { volume of soil settlement trough } \\ & V_{1, \mathrm{t}} \text { tunnel volume loss } \\ & z \text { depth } \\ & z_{\mathrm{t}} \text { tunnel depth } \\ & \varepsilon_{\mathrm{hc}} \text { compressive horizontal strain of the structure } \\ & \varepsilon_{\mathrm{ht}} \text { tensile horizontal strain of the structure } \\ & \varepsilon_{\mathrm{ult}} \text { ultimate strain to failure } \\ & \rho \text { density } \\ & \phi_{\mathrm{crit}} \text { critical state friction angle } \\ &\end{aligned}$

\section{REFERENCES}

Bilotta, E., Paolillo, A., Russo, G. \& Aversa, S. (2017). Displacements induced by tunnelling under a historical building. Tunn. Undergr. Space Technol. 61, 221-232, https://doi.org/ 10.1016/j.tust.2016.10.007.

Burland, J. (1995). Assessment of risk of damage to buildings due to tunnelling and excavations. In Proceedings of the $1 \mathrm{st}$ international conference on earthquake geotechnical engineering (IS-Tokyo'95) (ed. K. Ishihara), pp. 1189-1201. Tokyo, Japan: Balkema.

Burland, J. \& Wroth, C. (1974). Settlement of buildings and associated damage. In Proceedings of the conference on settlement of structures, pp. 611-654. London, UK: Pentech Press.

Camós, C., Molins, C. \& Arnau, O. (2014). Case study of damage on masonry buildings produced by tunneling induced settlements. Int. J. Architect. Heritage 8, No. 4, 602-625.

Caporaletti, P., Burghignoli, A. \& Taylor, R. (2006). Centrifuge study of tunnel movements and their interaction with structures. In Geotechnical aspects of underground construction in soft ground (eds K. J. Bakker, A. Bezuijen, W. Broere and E. A. Kwas), pp. 99-105. Boca Raton, FL, USA: CRC Press.

Dimmock, P. S. \& Mair, R. J. (2008). Effect of building stiffness on tunnelling-induced ground movement. Tunn. Undergr. Space Technol. 23, No. 4, 438-450.

Farrell, R. (2010). Tunnelling in sands and the response of buildings. $\mathrm{PhD}$ thesis, University of Cambridge, Cambridge, UK.

Farrell, R. \& Mair, R. (2010). Centrifuge modelling of the response of buildings to tunnelling. In Physical modelling in geotechnics (eds S. Springman, J. Laue and L. Seward), vol. 1, pp. 549-554. Boca Raton, FL, USA: CRC Press. 
Farrell, R. \& Mair, R. (2012). Centrifuge modelling of the response of buildings to tunnelling. In Geotechnical aspects of underground construction in soft ground (ed. G. Viggiani), pp. 343-351. Boca Raton, FL, USA: CRC Press.

Farrell, R., Mair, R., Sciotti, A., Pigorini, A. \& Ricci, M. (2012). The response of buildings to tunnelling: a case study. In Geotechnical aspects of underground construction in soft ground (ed. G. Viggiani), pp. 877-885. Boca Raton, FL, USA: CRC Press.

Franza, A. \& Marshall, A. M. (2016). Centrifuge modelling of piled structure response to tunnelling. In Eurofuge 2016, 3rd European conference on physical modelling in geotechnics (eds L. Thorel, A. Bretschneider, M. Blanc and S. Escoffier), pp. 313-318. Marne la Vallée, France: IFSTTAR.

Franzius, J. N., Potts, D. M., Addenbrooke, T. I. \& Burland, J. B. (2004). The influence of building weight on tunnelling-induced ground and building deformation. Soils Found. 44, No. 1, 25-38.

Franzius, J. N., Potts, D. M. \& Burland, J. B. (2006). The response of surface structures to tunnel construction. Proc. Instn Civ. Engrs - Geotech. Engng 159, No. 1, 3-17, http://dx.doi.org/ 10.1680/geng.2006.159.1.3.

Frischmann, W., Hellings, J., Gittoes, G. \& Snowden, C. (1994). Protection of the Mansion House against damage caused by ground movements due to the Docklands Light Railway extension. Proc. Instn Civ. Engrs - Geotech. Engng 107, No. 2, 65-76, http://dx.doi.org/10.1680/igeng.1994.26374.

Giardina, G., DeJong, M. J. \& Mair, R. J. (2015a). Interaction between surface structures and tunnelling in sand: centrifuge and computational modelling. Tunn. Undergr. Space Technol. 50, 465-478, https://doi.org/10.1016/j.tust.2015.07.016.

Giardina, G., Hendriks, M. A. \& Rots, J. G. (2015b). Sensitivity study on tunnelling induced damage to a masonry facade. Engng Struct. 89, 111-129, https://doi.org/10.1016/j.engstruct.2015. 01.042 .

Goh, K. \& Mair, R. (2011). Building damage assessment for deep excavations in Singapore and the influence of building stiffness. Geotech. Engng J. SEAGS \& AGSSEA 42, No. 3, 1-12.

Goh, K. \& Mair, R. (2012). The response of buildings to movements induced by deep excavations. In Geotechnical aspects of underground construction in soft ground (ed. G. Viggiani), pp. 903-910. Boca Raton, FL, USA: CRC Press.

Haigh, S. K. \& Madabhushi, S. G. (2002). Dynamic centrifuge modelling of the destruction of Sodom and Gomorrah. In Physical modelling in geotechnics - ICPMG '02 (eds P. Guo, R. Phillips and R. Popescu), pp. 507-512. Boca Raton, FL, USA: CRC Press.

Hansmire, W. H. \& Cording, E. J. (1985). Soil tunnel test section: case history summary. J. Geotech. Engng 111, No. 11, $1301-1320$.

Liu, G., Houlsby, G. \& Augarde, C. (2001). 2-dimensional analysis of settlement damage to masonry buildings caused by tunnelling. The Struct. Engr 79, No. 1, 19-25.

Loganathan, N., Poulos, H. \& Stewart, D. (2000). Centrifuge model testing of tunnelling-induced ground and pile deformations. Géotechnique 50, No. 3, 283-294, http://dx.doi.org/10.1680/ geot.2000.50.3.283.

Lu, Y., Bloodworth, A. G. \& Gleig, F. (2001). Behaviour of long structures in response to tunnelling. In Response of buildings to excavation induced ground movements, proceedings of the international conference held at Imperial College, London, UK (ed. F. M. Jardine), Special Publication 201, pp. 367-373. London, UK: CIRIA.

Madabhushi, S., Houghton, N. \& Haigh, S. (2006). A new automatic sand pourer for model preparation at University of Cambridge. In Physical modelling in geotechnics (eds C. W. W. Ng, Y. H. Wang and L. M. Zhang), pp. 217-222. Boca Raton, FL, USA: CRC Press.

Mair, R. (2013). Tunnelling and deep excavations: Ground movements and their effects. In Proceedings of the 15th European conference on soil mechanics and geotechnical engineering, geotechnics of hard soils - weak rocks (eds A. Anagnostopoulos, M. Pachakis and Ch. Tsatsanifos), part 4, pp. 39-70. Amsterdam, the Netherlands: IOS Press.

Mair, R. J. \& Taylor, R. N. (1997). Theme lecture: bored tunneling in the urban environment. In Proceedings of the 14th international conference on soil mechanics and foundation engineering, Hamburg, 6-12 September 1997, pp. 2353-2385. Rotterdam, the Netherlands: Balkema.

Mair, R. \& Taylor, R. (2001). Settlement predictions for Neptune, Murdoch, and Clegg Houses and adjacent masonry walls. In Building response to tunnelling: case studies from construction of the Jubilee Line Extension, London, volume 1: projects and methods (eds J. B. Burland, J. R. Standing and F. M. Jardine), pp. 217-228. London, UK: Thomas Telford.

Mair, R., Taylor, R. \& Burland, J. (1996). Prediction of ground movements and assessment of risk of building damage due to bored tunnelling. In Proceedings of the 4th international symposium on geotechnical aspects of underground construction in soft ground (ed. R. J. Mair), pp. 713-718. Rotterdam, the Netherlands: Balkema.

Marshall, A., Farrell, R., Klar, A. \& Mair, R. (2012). Tunnels in sands: the effect of size, depth and volume loss on greenfield displacements. Géotechnique 62, No. 5, 385-399, http:// dx.doi.org/10.1680/geot.10.P.047.

Melis, M. \& Rodriguez Ortiz, J. (2001). Consideration of the stiffness of buildings in the estimation of subsidence damage by EPB tunnelling in the Madrid Subway. In Response of buildings to excavation induced ground movements, proceedings of the international conference held at Imperial College, London, UK (ed. F. M. Jardine), Special Publication 201, pp. 387-394. London, UK: CIRIA.

Peck, R. B. (1969). Deep excavations and tunnelling in soft ground. Proceedings of the 7th international conference on soil mechanics and foundation engineering, Mexico City, Mexico, pp. 225-290.

Potts, D. \& Addenbrooke, T. (1997). A structure's influence on tunnelling induced ground movements. Proc. Instn Civ. Engrs - Geotech. Engng 125, No. 2, 109-125, http:// dx.doi.org/10.1680/igeng.1997.29233.

Ritter, S., Giardina, G., DeJong, M. J. \& Mair, R. J. (2017). Centrifuge modelling of building response to tunnel excavation. Int. J. Phys. Model. Geotech., http://dx.doi.org/10.1680/jphmg. 16.00053 .

Schmidt, B. (1969). Settlements and ground movements associated with tunneling in soil. $\mathrm{PhD}$ thesis, University of Illinois, Urbana-Champaign, IL, USA.

Son, M. \& Cording, E. J. (2007). Evaluation of building stiffness for building response analysis to excavation-induced ground movements. J. Geotech. Geoenviron. Engng 133, No. 8, 995-1002.

Standing, J. (2001). Elizabeth House, Waterloo. In Building response to tunnelling: case studies from construction of the Jubilee Line Extension London, volume 2: case studies (eds J. B. Burland, J. R. Standing and F. M. Jardine), pp. 735-754. London, UK: Thomas Telford.

Taylor, R. \& Grant, R. (1998). Centrifuge modelling of the influence of surface structures on tunnelling induced ground movements. In Tunnels and metropolises (eds A. Negro (Jr) and A. A. Ferreira), pp. 261-266. Rotterdam, the Netherlands: Balkema.

Viggiani, G. \& Standing, J. (2001). The treasury. In Building response to tunnelling: case studies from construction of the Jubilee Line Extension London, volume 2: case studies (eds J. B. Burland, J. R. Standing and F. M. Jardine), pp. 401-432. London, UK: Thomas Telford.

Vorster, T. (2002). The effects of tunnelling on buried pipes. $\mathrm{PhD}$ thesis, University of Cambridge, Cambridge, UK.

White, D., Take, W. \& Bolton, M. (2003). Soil deformation measurement using particle image velocimetry (PIV) and photogrammetry. Géotechnique 53, No. 7, 619-632, http://dx.doi.org/10.1680/geot.2003.53.7.619. 